\title{
Robotics, imaging, and artificial intelligence in the catheterisation laboratory
}

\author{
Rafael Beyar ${ }^{1,2 *}$, MD, DSc; Justin E. Davies ${ }^{3}, \mathrm{MD}, \mathrm{PhD}$; Christopher Cook${ }^{4}, \mathrm{MBBS}, \mathrm{PhD}$; \\ Dariusz Dudek ${ }^{5,6}, \mathrm{MD}, \mathrm{PhD}$; Paul A. Cummins ${ }^{7}, \mathrm{BSc}$; Nico Bruining ${ }^{8}, \mathrm{PhD}$
}

1. The Ruth \& Bruce Rappaport Faculty of Medicine, Technion-Israel Institute of Technology, Haifa, Israel; 2. Rambam Health Care Campus, Haifa, Israel; 3. Hammersmith Hospital, Imperial College NHS Trust, London, United Kingdom; 4. Essex Cardiothoracic Centre, Essex, United Kingdom; 5. Institute of Cardiology, Jagiellonian University Medical College, Krakow, Poland; 6. Maria Cecilia Hospital, GVM Care \& Research, Cotignola (RA), Italy; 7. Department of Cardiology, Erasmus MC, Rotterdam, the Netherlands; 8. Clinical Epidemiology and Innovation, Thoraxcenter, Department of Cardiology, Erasmus MC, Rotterdam, the Netherlands

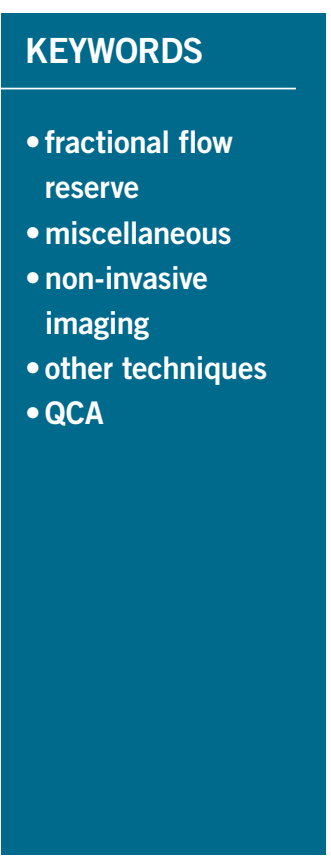

\section{Abstract}

The catheterisation laboratory today combines diagnosis and therapeutics, through various imaging modalities and a prolific list of interventional tools, led by balloons and stents. In this review, we focus primarily on advances in image-based coronary interventions. The X-ray images that are the primary modality for diagnosis and interventions are combined with novel tools for visualisation and display, including multiimaging co-registration modalities with three- and four-dimensional presentations. Interpretation of the physiologic significance of coronary stenosis based on prior angiographic images is being explored and implemented. Major efforts to reduce X-ray exposure to the staff and the patients, using computer-based algorithms for image processing, and novel methods to limit the radiation spread are being explored. The use of artificial intelligence (AI) and machine learning for better patient care requires attention to universal methods for sharing and combining large data sets and for allowing interpretation and analysis of large cohorts of patients. Barriers to data sharing using integrated and universal protocols should be overcome to allow these methods to become widely applicable. Robotic catheterisation takes the physician away from the ionising radiation spot, enables coronary angioplasty and stenting without compromising safety, and may allow increased precision. Remote coronary procedures over the internet, that have been explored in virtual and animal studies and already applied to patients in a small pilot study, open possibilities for sharing experience across the world without travelling. Application of those technologies to neurovascular, and particularly stroke interventions, may be very timely in view of the need for expert neuro-interventionalists located mostly in central areas. 


\section{Abbreviations}

3D

three-dimensional

4D four-dimensional

Al artificial intelligence

CT computed tomography

DICOM Digital Imaging and Communications in Medicine (medical imaging standard)

EU European Union

FDA Food and Drug Administration

IVUS intravascular ultrasound

MRI magnetic resonance imaging

OCT optical coherence tomography

PCI percutaneous coronary interventions

SPECT single-photon emission computed tomography

\section{Introduction}

The entire catheterisation laboratory environment is undergoing a major revolution. In recent years we have seen remarkable innovations leading to a marked improvement to our imaging modalities and methodologies for analysing and visualising cardiovascular structures. While X-ray hazards continue to pose a constant threat to medical personnel and patients, new modalities for reducing radiation exposure are constantly being developed. Computational and artificial intelligence (AI)-based interpretation of coronary images is now being explored and applied to our patients in both the research and clinical arenas. Robotic interventions, originally developed and implemented in the surgical arena, are now entering the catheterisation laboratory.

This review focuses on current and future trends in coronary interventions, with particular emphasis on the X-ray fluoroscopy environment, which is being enhanced by new imaging and visualisation methodologies that leverage machine learning and AI to help advanced patient diagnoses and therapeutics. Integration of physiological measurements into our clinical paradigm help tremendously in creating better decision-making tools for interventionalists. Since these new methodologies are being used within catheterisation laboratories and the harsh environment of radiation exposure, recent developments to reduce that exposure will be discussed. Recently developed robotics and automation for percutaneous coronary and neurovascular procedures aim to remove the operator from this hostile environment and increase procedural precision. These developments have opened up a new world of possibilities regarding remote procedures and partial or complete automation.

\section{ADVANCED IMAGING TECHNOLOGIES AND VIRTUAL REALITY IN INTERVENTIONAL CARDIOLOGY}

Cardiovascular imaging has evolved tremendously over the past two decades. Today, imaging is crucial in both diagnosis and as the primary guidance tool during interventions. The Central illustration lists the various imaging modalities that are used before, during, and following coronary and cardiac interventions with a few visual examples. Use of these technologies in various forms, as well as the overriding AI surveillance, are discussed below.
The primary imaging modalities during coronary interventions are $\mathrm{X}$-ray fluoroscopy and angiography. With the advances in digitisation of coronary angiography at the end of the 1990s, computerassisted image analysis became feasible. This enabled objective measurement of coronary obstructions by quantitative coronary angiography. It was a breakthrough for routine diagnostic evaluations and for providing novel therapeutic methodologies of the coronary arteries ${ }^{1,2}$. Quantitative coronary angiography is now integral to every interventional laboratory.

Digital methods for on-line image analysis and visualisation have been developed to aid the physician during percutaneous coronary interventions (PCI). Since stent visibility is often suboptimal using X-ray fluoroscopy, digital image processing methods for stent enhancement have been developed. A comprehensive review of stent enhancement ${ }^{3}$ shows its use for assessing stent strut damage, stent overlap, stent failure, aorto-ostial lesions, and bifurcations. Stent enhancement offers ease of use, minimal time required for the analysis, no additional cost, and immediate enhanced image interpretation.

Static vascular roadmaps are regularly used during peripheral interventions where blood vessel movement is minimal. However, in coronary procedures, where motion of the vessels prevents overlay of static roadmaps, navigation within the vessels is done by visual comparison to a displayed angiographic image, and additional contrast injections for pathway verification during wire passage, balloon, and stent placement. The Dynamic Coronary Roadmap (Philips Healthcare, Best, the Netherlands) is a recent development that offers real-time, dynamic overlay of the coronary tree on the fluoroscopic image used for PCI navigation (Central illustration, B). The feasibility of this approach was evaluated in a single-centre study ${ }^{4}$ which showed that it provides a sufficient roadmap for the majority of patients. Yabe et $\mathrm{al}^{5}$ explored the clinical impact of this technology compared to the traditional approach in a total of 130 consecutive patients undergoing elective PCI. The Dynamic Coronary Roadmap compared to the traditional approach was associated with a significant reduction in contrast volume (22\%) and fluoroscopy time $(30 \%)$, despite similar clinical and procedural characteristics. Clearly, such technologies to assist the physician in better image analysis may have a significant impact on the efficiency of the procedure and on patient outcomes.

Besides standard coronary angiography, the past 20 years have also seen the introduction of other imaging methods to the interventional laboratory, such as intravascular ultrasound (IVUS) and optical coherence tomography (OCT). Outside of the interventional laboratory, cardiovascular imaging advances using multislice three-dimensional (3D) computed tomography (CT) were implemented to advance the planning of complex interventional procedures. A few examples include planning for transcatheter aortic valve replacement ${ }^{6}$ (Central illustration, A), septal occlusion for treatment of hypertrophic cardiomyopathy, and a clinical decision-making tool that uses flow equations to calculate non-invasive coronary flow reserve ${ }^{7}$. One of the most challenging 


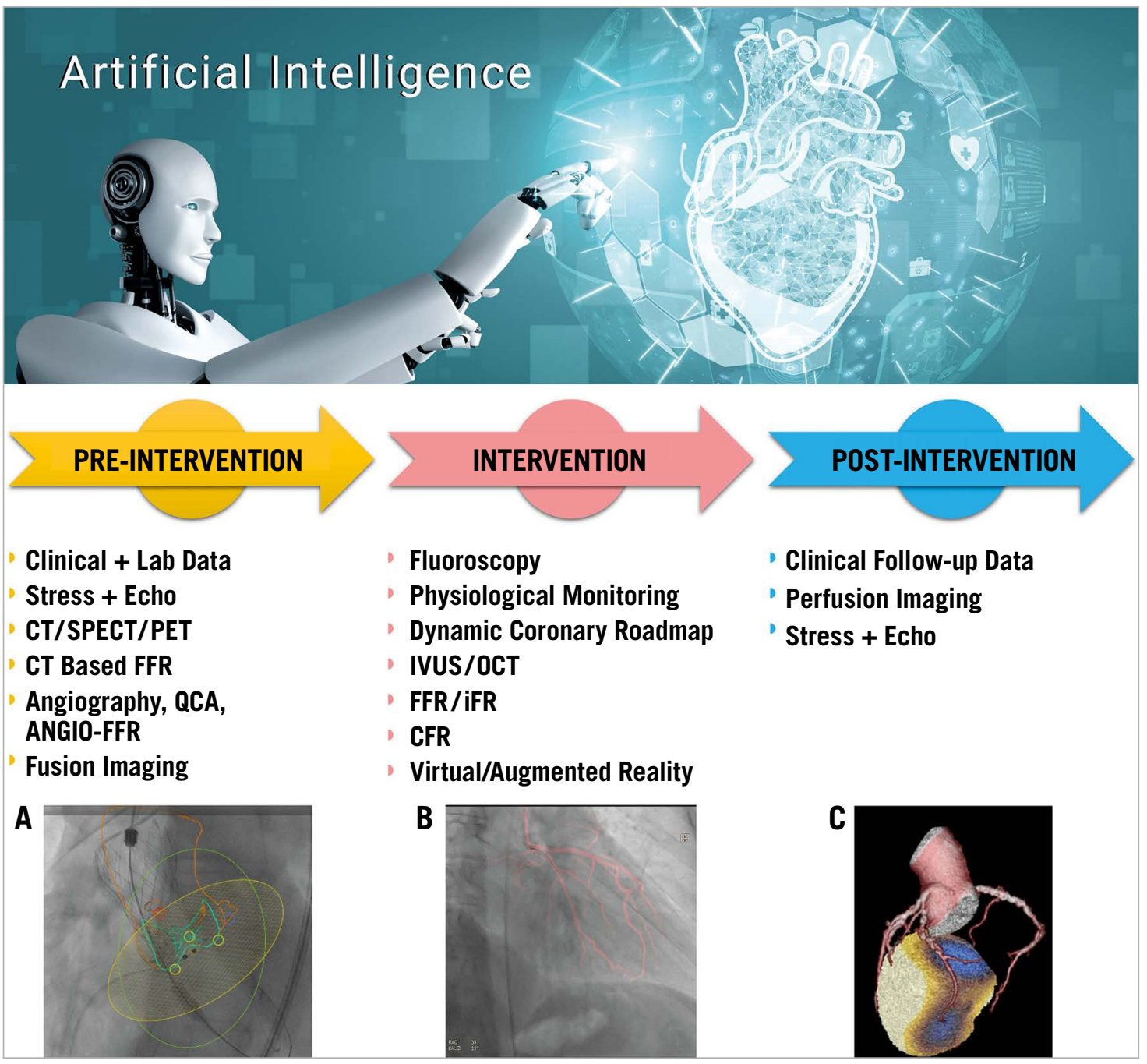

Central illustration. Current imaging and physiology methods pre-, during, and post intervention. Pre-intervention multimodality 3D imaging may be obtained to allow better understanding and planning of the procedure. Fusion of the angiographic images with CT data enhances $3 D$ understanding of procedures such as TAVR (A). During the procedure, fluoroscopy is the main tool for guidance, but various intravascular methods may be combined with angiographic procedures. Dynamic Coronary Roadmap is a novel tool to aid navigation during the procedure (B). Post-procedure imaging varies between different imaging modalities, with or without flow reserve challenges. An example of SPECT CT is shown in panel C. AI can access all these data in the background to aid the physician in planning and execution of an optimal patient intervention.

image-based coronary artery analyses in the past was the identification of vulnerable plaque ${ }^{8}$. This challenge led to a number of innovative invasive $e^{9,10}$ and non-invasive ${ }^{11,12}$ image-based technologies.

Powerful computer technologies have made it possible to merge different imaging modalities ${ }^{13}$. For example, IVUS and OCT are intrinsically planar, but can be visualised using their original curvature in volumetric $3 \mathrm{D}$ as well as dynamically in four dimensions (4D), with the appropriate data set. Besides 3D visualisation, which in itself has major advantages, the reconstructed data can also build patient-specific computer models. These models can be used for additional calculations and analysis using biomechanical flow simulations, which enable shear stress distribution measurements in the coronary arteries. This can be used as a clinical risk predictor for plaque progression or rupture in specific segments ${ }^{8}$.
The addition of AI will help in real-time image analysis, as well as providing real-time clinical, laboratory, and other important information. Figure 1 provides a schematic flow chart of the integration of imaging in the catheterisation laboratory applying AI to support the physician's decision-making process.

\section{ARTIFICIAL INTELLIGENCE AND COMPUTATIONAL CARDIOLOGY}

The potential benefits of using AI in medicine are now being extensively pursued ${ }^{14}$. Its implementation and use will dramatically change the medical landscape. There are some promising new and successful applications related to electrocardiogram (ECG) analyses $^{15}$, as well as some new developments in echocardiography ${ }^{16}$. Several excellent sources of information regarding the basic 


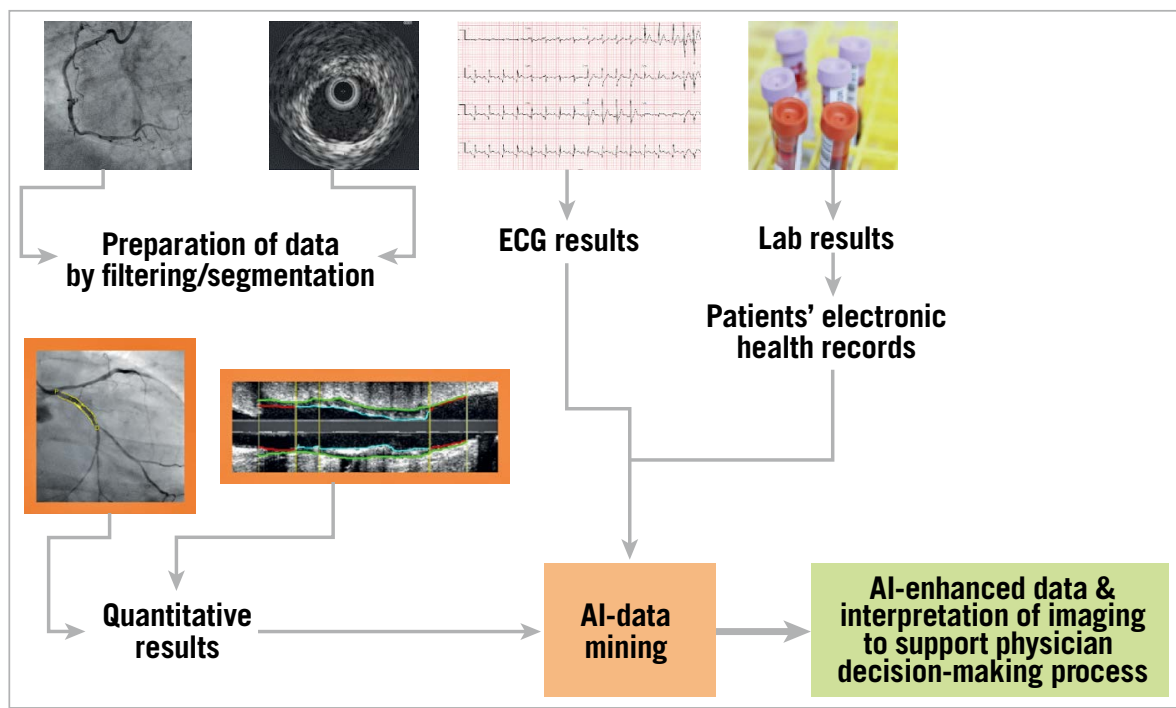

Figure 1. Schematic presentation of the use of artificial intelligence (AI) with data mining in the interventional laboratory. Integration of X-ray and intravascular imaging data, ECG, laboratory results, and the patient's electronic health records are analysed by AI. Imaging interpretation will be supported by AI and enhanced by real-time clinical, laboratory and other important information to support the physician's decision-making process.

principles of $\mathrm{AI}$ and its applications in medicine and interventional cardiology are now available ${ }^{17,18}$.

AI will have utility in analysing the ever-growing amount of patient data being generated. Potentially, leveraging this big data using AI in the catheterisation laboratory will markedly increase prediction accuracy and clinical decision making for several treatment modalities. Currently, available databases are dedicated strictly to the specific imaging modality used, with limited information regarding the clinical and laboratory data of patients. In the future, a critical AI enhancement will be the addition of clinical and laboratory data to the imaging data to enhance system precision further. The algorithms will improve themselves based on machine learning and deep learning algorithms. However, to achieve this goal, large high-quality databases with accurate annotations are needed. Currently, such large data sets of interventional images are generally lacking when, for example, compared to the world of ECG AI analysis ${ }^{19}$. One proposal for achieving this goal is to build a digital twin of each patient as a computer model that includes all available clinical, imaging, and laboratory data. This, combined with AI analysis, could lead to applications for actualising precision medicine for our patients ${ }^{14}$.

\section{COMPUTER VISION}

While we are already seeing impressive integration of different imaging modalities in the interventional laboratory, they are still limited to predominantly two-dimensional views. Fusion imaging between the various non-invasive imaging modalities, e.g., ultrasound, magnetic resonance imaging (MRI), single-photon emission computed tomography (SPECT), and CT, is difficult to achieve, though significant progress has been made ${ }^{20}$. An example of a SPECT CT fusion image is shown in the Central illustration, panel C. Fusion of prior CT 3D information with fluoroscopy is of particular benefit in structural heart interventions (Central illustration, A), as well as in certain cases with challenging chronic total occlusions ${ }^{21}$ that require clear visualisation of the entire vessel.

Fusion of angiographic images with IVUS, OCT, and physiologic measurements has been widely applied. This methodology, which is of interest in research studies that further characterise the atherosclerotic plaque ${ }^{22}$, has great potential for better guidance and precision in robotic interventions, by superimposing data received from such tools on angiography to achieve full plaque coverage while avoiding unnecessary treatment of non-critical lesions in long diffuse disease.

Commercially available software for registration of both CT and MRI images to fuse rapidly with fluoroscopic imaging is now available (VesselNavigator system; Philips Healthcare) ${ }^{23}$. This imaging overlay technology enables $3 \mathrm{D}$ reconstruction of structures of interest (Central illustration, A), providing guidance for transcatheter interventions in structural procedures. In a single-centre study, intervention for congenital heart diseases with rapid registration proved feasible, aided planning of angiographic angles, and offered precision in guidewire manipulations ${ }^{24}$.

The next step to more realistic 3D/4D renderings and visualisation could be holography ${ }^{25}$. However, this requires a prospective reconstruction based on prior CT or MRI before the patient enters the interventional laboratory. The optimal pathway to achieve this would be generation of real-time virtual and mixed reality visualisations. Devices such as the HoloLens ${ }^{\mathrm{TM}}$ (Microsoft, Redmond, WA, USA) could provide such a set-up ${ }^{26}$. Figure 2 provides an example of such a set-up, with the semi-transparent 3D hologram displayed in real time in front of the cardiologist, thereby assisting with the procedure. These ideas have led to a new interdisciplinary field, referred to as "computer vision", which deals with 


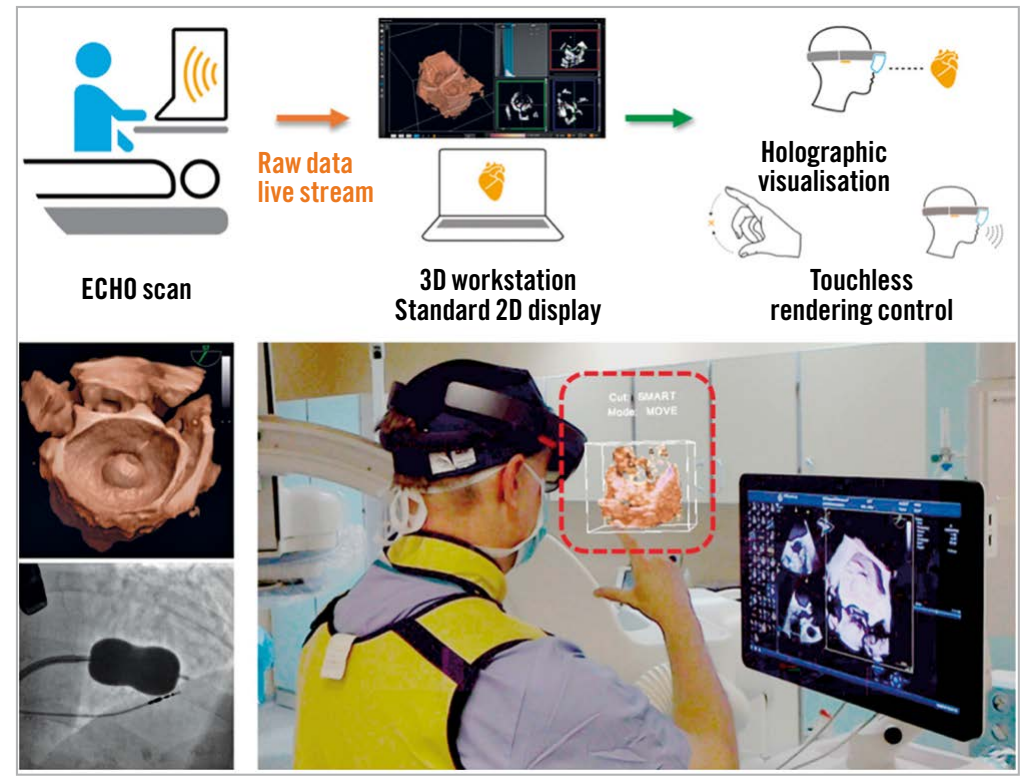

Figure 2. The HoloLens mixed reality display (Microsoft, Redmond, WA, USA) is used to overlay 3D data on a hologram reality view during a balloon mitral valve intervention. Data obtained for ultrasound echocardiography are visible as a semi-transparent holographic cube positioned in front of the echocardiographist and shared by an interventional cardiologist. Reproduced with permission from Kasprazak et $\mathrm{al}^{26}$, and from the European Society of Cardiology. All rights reserved.

how computers extract a high level of understanding from digital images, similar to how we as humans do. This technology uses multiple information sources at once, something not possible for the human operator ${ }^{27}$.

\section{ARTIFICIAL INTELLIGENCE AND INTERVENTIONAL IMAGING}

Krittanawong et $\mathrm{al}^{28}$ presented an overview of $\mathrm{AI}$ in precision cardiovascular medicine. One example, although not widely used today, is that of myocardial blushing in image analysis. However, it may well be possible to use it in the clinical setting, if online AI-based analysis can speed up the analysis process ${ }^{29}$. Complete reconstruction and analysis of the entire coronary artery tree can be the input for robotically assisted procedures, as described by Sardar et $\mathrm{al}^{30}$. Another important area is the training of interventionists for complex procedures. Cates et $\mathrm{al}^{31}$ presented a computerbased simulation using real patient data as a procedure rehearsal, which could improve actual procedural performance. Several currently practical available deep learning applications for cardiovascular image analysis have been described by Litjens et $\mathrm{al}^{32}$. The number of AI-related developments in interventional cardiology is exploding and exponential growth is expected soon, for example, the use of AI to detect fractional flow reserve through diagnostic angiography automatically ${ }^{33}$.

\section{MEDICO-LEGAL CONCERNS}

Medico-legal issues for AI-based decisions are still under debate. For example, will physicians be legally comfortable with treatment decisions based on AI, since the physician remains liable? The safety and effectiveness of such algorithms have been dealt with recently by the United States Food and Drug Administration (FDA) and European Union (EU), which have issued regulatory guidelines for $\mathrm{AI}$ implementations, requiring prior evaluation before AI software can be used as a medical device ${ }^{34}$. While many questions need to be answered with respect to AI in medicine, two of the main concerns are "black-box" results, which do not necessarily relate to pathophysiological mechanisms, and questions regarding the future role of the physician within the AI environment. We have to ensure that we will not lose our "clinical sense" in getting used to relying on AI-based diagnosis and therapeutics.

\section{FUTURE STEPS}

Applying AI technology to big data analysis requires a high degree of standardisation and integration of the various data sources within a hospital, between hospitals, and access to prior data from patient referrals, as well as outcome data from outpatient followup. In most countries, each medical institute or group of institutes uses a different patient record system; the integration of imaging databases with clinical and laboratory databases within institutions is limited. Standardisation protocols are required to allow the integration and use of various data sources. This should not be limited to local/domestic sources but extended to include international sources as well.

We must standardise data acquisition and analyses protocols. This in itself is a challenge, since implementation of digital standards within the clinical setting has been slow. By example, the medical imaging standard - Digital Imaging and Communications in Medicine (DICOM) - has been successfully adopted widely ${ }^{35}$. However, because of the variability of imaging devices, some vendors are not implementing identical protocols of data acquisition in their devices. Using historic data can be problematic, as data "quality" often cannot be controlled. As mentioned earlier, the crucial element here is to create large quality databases with accurate and reliable annotations. 
The process of algorithm validation, mainly with application to a specific patient, is complicated and demanding. Medicine in general is a conservative discipline and tends to apply novel methods after thorough corroboration. To ensure that AI can be successfully implemented into our cardiology practice, there must be a commitment to show accuracy through validation processes ${ }^{36,37}$. Routes to validate the AI-based decision processes should be explored and compared to expert decisions coming out of the catheterisation laboratory. Such validation is clearly a cross-disciplinary effort. Only when this is achieved will physicians have the confidence to embrace AI applications and AI-derived clinical decision-making processes. Finally, disparate components of the medico-legal and ethical considerations need to be resolved ${ }^{38}$.

\section{FROM X-RAY IMAGING TO RADIATION REDUCTION}

In the ongoing effort to provide more advanced transcatheter therapies to our patients, consideration must be given to the potentially detrimental physical effects of cumulative radiation exposure amongst catheter laboratory operators and staff. This is of growing importance, given the increasing complexity of coronary interventional procedures being offered, as well as the continued expansion in structural cardiology procedures in contemporary interventional cardiology practice.

Staff education and training in the fundamental physics of mitigating excess radiation exposure (e.g., maximising the distance from the radiation source, avoiding steep working angulations during procedures, etc.) continues to form the foundation of safe radiation practice in the catheterisation laboratory. However, innovations in technology, particularly at the dawn of the AI era, hold significant promise for optimising fluoroscopic interventional procedures and reducing occupational radiation exposure.

Traditional approaches to radiation reduction, apart from the education of the operators, have primarily involved hardware modifications and shield-based interventions. This attunes all major manufacturers of angiography systems to the need to compete on radiation reduction measures. Accordingly, research and development aimed at improving X-ray tube designs and radiation detector sensitivities is ongoing. Ancillary hardware inventions continue to evolve, often as novel approaches to architectural shielding of the operator from ionising rays. This is being realised by the development of a ceiling-suspended radiation protection system (Zero-Gravity ${ }^{\mathrm{TM}}$; Biotronik, Berlin, Germany) that replaces the traditional wearable lead apron with a thick transparent lead glass armour, allowing the operator to reach and manoeuvre the catheters while fully shielded ${ }^{39}$. Finally, the most radical approach to reducing occupational radiation exposure is the adoption of complete robotic systems that can facilitate the complete removal of the operator from the radiation environment (described below).

Because of the fundamental physical nature of working with ionising radiation, refinements in X-ray hardware technologies will always remain a central target for innovation. However, the catheterisation laboratory of the near future is likely to feature a host of software innovations that will either directly or indirectly reduce radiation exposure. Analogous to the updating of a smartphone's operating system, software innovations designed to integrate into hardware systems may permit new and extended applications using existing X-ray equipment.

One of the most high-profile examples of recent software innovations for incorporation into the angiography suite is the integration of eye-tracking technology to focus the X-ray beam intuitively towards the region of most interest. The premise of this technology is that it mimics the organisation and function of the human visual system - where the most detailed imaging is required only in the central vision, with the peripheral vision providing less detail. The technology utilises semi-transparent filters to focus the X-ray beam on the area of the image that the operator's eyes are focused on while delivering less radiation to the peripheral areas where it is not needed. Such an approach in a swine model has reportedly reduced operator irradiation by approximately $75 \%$ without interfering with performing fluoroscopically guided interventional procedures $^{40}$.

Taking computational integration in the catheterisation laboratory to an even higher level, future software innovations will very likely capitalise on AI image processing capabilities. Specifically, AI "computer vision" algorithms can recognise images or features in multidimensional data sets and particularly apply those to fluoroscopic imaging. Early examples of computer vision algorithms have shown promise for real-world use, having been able to show accurate detection of stenosis characteristics, and abnormalities such as dissection or thrombus ${ }^{41}$. With development, they may then use such labelled data for optimal suggestion of the ideal angiographic projection and to acquire the minimal number of angiographic images to exclude disease, etc., thereby reducing radiation analogous to the practice of an experienced human operator.

Perhaps the ultimate goal of AI in the catheterisation laboratory of the future is the notion of a series of algorithms working together to develop and support human clinical decision making - specifically, the process of computer vision labelled data, being interpreted by machine-learning algorithms to provide intelligent diagnostic and procedural decisions. However, currently, such applications remain in their infancy. One such emerging AI technology relevant to radiation reduction is one of a series of algorithms being developed by Cerebria (St Albans, United Kingdom ${ }^{42,43}$. They have trained a neural network to identify automatically the ideal collimation settings of a particular angiographic frame. The potential of such a technology is the automatic and optimal reduction in radiation exposure for patients and staff during procedures, with the additional benefit of improved image quality.

In summary, the catheterisation laboratory of the twenty-first century is likely to provide a significantly lower radiation environment than the current ones. Innovations in hardware, and particularly AI-based software, will ensure the continued provision of transcatheter therapies with increased radiation safety for operators and patients alike. 


\section{ROBOTICS AND AUTOMATION}

\section{HISTORY OF SURGICAL ROBOTICS}

One of the first robotic medical applications was aimed at surgical procedures in the battlefield. Originally developed by DARPA, it aimed to provide a "telepresence" for remote procedures ${ }^{44}$. Subsequently, a private-public partnership and mergers between companies saw the entry of da Vinci surgical robotics into the medical field, aimed at extending the human interface to improve patient care and outcomes by enabling smaller incisions, improving precision at the surgical site, and enabling remote procedures. The first surgical robotic procedure was performed in $1997^{45}$ and today robotic surgery is widely used in various surgical and interventional fields. The original concept of remote "telepresence" surgery was first used for a cholecystectomy in 2001 between the USA and France, through a direct transatlantic point-to-point communication line allowing $155 \mathrm{~ms}$ lag time ${ }^{46}$. Interestingly, despite its success, remote surgical procedures did not gain clinical acceptance. Legal and licensing responsibilities, lack of physician to patient interaction, need for specifically dedicated communication lines and the need to resolve unexpected emergencies safely may be some of the reasons why remote surgical robotics has not yet been clinically adopted. Looking to the future, a game changer leading to acceptance may be the stronger unmet need due to the shortage of experts in some medical disciplines, together with technological optimisation of communication speed.

\section{CORONARY ROBOTICS: FROM THE EARLY DAYS TO FDA APPROVAL}

The field of PCI was born when Andreas Gruentzig performed the first coronary balloon angioplasty in $1977^{47}$. Four decades later, the way PCI is performed remains the same, with the operators standing next to the patient within the harsh X-ray environment, partially protected by shields and wearing a lead apron and additional accessories. The hazardous effects of radiation range from a higher likelihood of cancer ${ }^{48}$, to brain tumours ${ }^{49}$, cataracts $^{50}$, and spine problems ${ }^{51}$, to name but a few.

Coronary robotics evolved to protect the operators and enhance precision. Navigation of coronary wires using a magnetic field ${ }^{52}$ was tested in patients, with a $93 \%$ success rate in 439 lesions ${ }^{53}$. However, apart from the wire navigation, the rest of the procedure had to proceed manually. The concept of a fully robotic PCI procedure was introduced by Beyar and colleagues ${ }^{54,55}$, who proposed a remote navigation system, with the wire, balloon, and stent (Figure 3A) manœuvred via a bedside unit using a single joystick on a remotecontrolled unit (Figure 3B). After proof of safety and feasibility in animals $^{54}$, the first cohort of 18 coronary stenosis patients was treated with this system, by robotically navigating the wire across the lesion, advancing the balloon to its position, and performing stent implantation, with post-dilatation as needed. All cases were successful and there was only one complication, i.e., a system malfunction, necessitating a manual procedure instead ${ }^{55}$. The remote navigation system

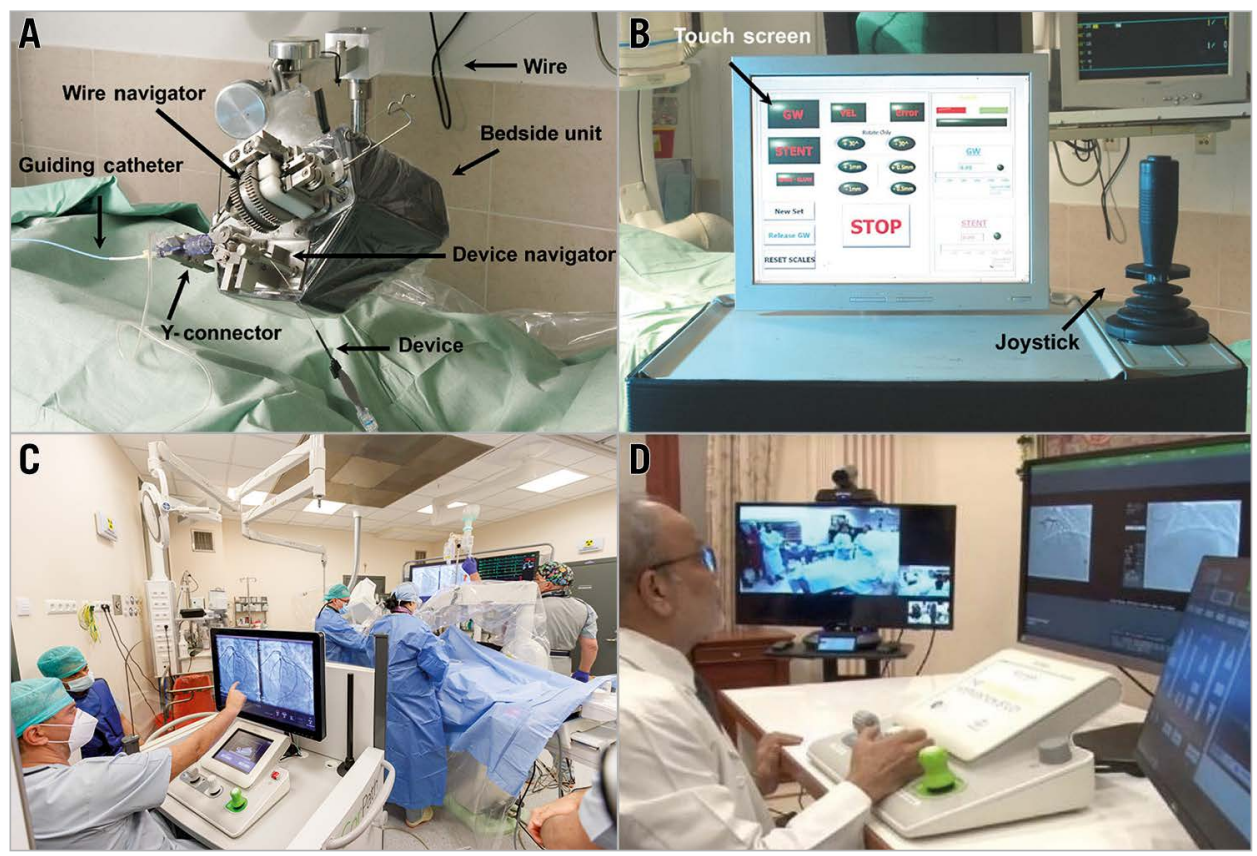

Figure 3. The evolution of the robotic PCI system and concept. A) The original Remote Navigation System manipulating wire and device are controlled at the console by a joystick (B). Reprinted from Beyar et al ${ }^{55}$, with permission from Elsevier. C) The current CorPath GRX control station ${ }^{60}$ is positioned within a shielded cockpit in the catheterisation laboratory with the operator console controlling the wire, the device, and the guide catheter (taken during robotic PCI at the Interventional Cardiology Center, Jagiellonian University Hospital, Poland). D) Set-up for the first remote catheterisation performed by Dr Tejas Patel in Ahmadabad, India. The control station is located $35 \mathrm{~km}$ away from the catheterisation laboratory, with the robotic arm at the patient side. The video of the patient room and the monitor screen are transmitted via the internet. From Patel et al ${ }^{79}$ [CC BY-NC-ND 4.0]. 
provided continuous, as well as discrete $1 \mathrm{~mm}$ steps of either wire or balloon movements, thereby allowing precise movements of the device for accurate lesion length measurement and stent placement.

On the basis of that system, the CorPath $200^{\mathrm{TM}}$ system (Corindus Inc., a Siemens Healthineers Company, Waltham, MA, USA) was developed. For this set-up, the bedside unit was hooked to the patient table and the dual control unit (wire and device) was placed in a protected cockpit within the catheterisation laboratory. Following animal experiments, the system was then used in eight patients to prove safety and feasibility ${ }^{56}$. This was followed by a pivotal study in 164 patients $^{57}$ that showed $98.8 \%$ technical success and $95.2 \%$ reduction of radiation to the operator. In 2012, the FDA approved the system based on this study.

\section{BEYOND THE FDA}

Extensive use of the robotic system in multiple sites created solid literature regarding the use of the system in real-world scenarios. Experience in complex lesions ${ }^{58}$ showed that partial or full conversion of the procedure to a manual operation was required in $18.5 \%$ of the cases. Since the lack of a guide catheter control was identified as a major limiting factor ${ }^{59}$, the second-generation system was designed with a triple control (wire, device, and guide catheter) (CorPath ${ }^{\circledR}$ GRX; Corindus Inc.) (Figure 3C) and received FDA approval in $2016^{60}$. The initial experience in 40 consecutive patients showed a high success rate ${ }^{61}$. Feasibility of robotic PCI in unprotected left main lesions was reported ${ }^{62}$, including the use of an Impella ${ }^{\circledR}$ circulatory support system (Abiomed, Danvers, MA, USA) during robotic high-risk angioplasty ${ }^{63}$. The system also allowed use of phased-array IVUS, laser atherectomy ${ }^{64}$, and other devices. Comparison of 6- and 12-month outcomes between robotic and manual PCI in complex lesions ${ }^{65}$ showed equivalence between procedures $^{66}$. Geographical miss was markedly reduced by robotic assistance ${ }^{67}$. Positive experience with robotic PCI for chronic total occlusion has also been reported ${ }^{68,69}$. Recently, the use of robotic PCI in a suspected COVID-19 patient in need of urgent coronary artery interrogation to minimise the risk of viral exposure to the staff was reported ${ }^{70}$. Application of robotic angioplasty to the femoral-popliteal arteries (RAPID trial) showed 100\% success in 20 patients $^{71}$. Robotic PCI has been reviewed as a paradigm change in interventional cardiology ${ }^{72}$; however, the need for randomised controlled studies to prove its benefits was clearly indicated ${ }^{73}$.

Mangels et $\mathrm{al}^{74}$ compared resource utilisation in robotic PCI $(n=56)$ with manual PCI $(n=108)$. They report higher direct supply costs attributed to single-use robotic components, without a significant difference in total hospitalisation or catheterisation laboratory cost for robotic PCI. Similar fluoroscopy time, procedural time, and total number of stents with a lower volume of contrast were reported for robotic PCI.

Recently, fluoroscopy time and contrast use were compared by a propensity score-matched analysis between robotic (310 patients) and manual PCI (686 patients) ${ }^{75}$. Robotic PCI was associated with a significant reduction in patient exposure to radiation, no increase in fluoroscopy time or in contrast utilisation, and a minor increase in procedure duration compared with traditional PCI.
FROM THE CATH LAB TO THE CONTROL ROOM TO REMOTE INTERNET PROCEDURES

While the majority of interventional procedures are set up with the control station placed within a protected cockpit in the catheterisation laboratory next to the patient table, some operators prefer performing PCI with the console placed in the control room. The concept of a remote procedure, during which the operator is outside and potentially distant from the patient procedure room was initially tested in a swine model within the Mayo Clinic, using local communication ${ }^{76}$ with full success in 52 experiments. Latency effects for up to $1,000 \mathrm{~ms}$ were tested; a detrimental effect was observed only for a latency greater than $250 \mathrm{~ms}$. In parallel, Madder and colleagues ${ }^{77}$ showed the feasibility of remote telestenting through a hard-wired connection to an adjacent room in 20 patients, with $95 \%$ success. Following prior simulation and in vivo evaluation of robotic PCI over the internet ${ }^{78}$, the first remote cases were performed by Dr Patel in Ahmadabad, India, who performed PCI in five patients from $35 \mathrm{~km}$ away through a regular wired connection ${ }^{79}$. The remote operator worked at the standard control station and was able to see the entire catheterisation laboratory, the angiographic images, and the haemodynamic monitors. The set-up of the remote site with Dr Patel is shown in Figure 3D. Internet connection allowed streaming video visualisation of the procedure and uneventful communications between the remote site and the catheterisation laboratory. A diagram of modes of remote operation is shown in Figure 4. In the catheterisation laboratory, the robotic arm is hard-wired to the operator console where it can be placed in a shielded cockpit next to the patient or in the adjacent control room. In addition, a duplicate console in a remote location can be operated by experienced interventionalists through standard internet, $5 \mathrm{G}$, or other fast and broadband communication channels.

The ability to perform efficient and safe procedures over the internet depends on the lag time, which is unfelt for latencies less than $250 \mathrm{~ms}$. The measured latency in the human study was $53 \mathrm{~ms}^{80}$. Recently, 5G wireless networks have been opening a whole range of possibilities for remote procedures. A test performed across the USA using the $5 \mathrm{G}$ network indicated the feasibility of performing robotic procedures remotely with a measured latency of $121 \mathrm{~ms}$ compared to $67.8 \mathrm{~ms}$ in a wired connection, both imperceptible latencies ${ }^{80}$. The remote experience in surgery and PCI clarifies that the technical aspects for remote PCI have been solved for both wired and wireless communication. Other aspects of remote operation, including licensing, liabilities, and the required presence and level of expertise of the staff at the remote site require further investigation. User experience of remote interventions includes a combination of speech and image synchronisation. Currently, latency can be a problem when transferring over long distances. Future developments must overcome this issue and facilitate an immediate response of the robotic system with undetectable latency. Further evaluation in practical clinical settings over long distances is required if we are to see an increase in the implementation of remote procedures. Obviously, the ability to manage problems such as system failure or broken communication safely should be a mandatory requirement. 


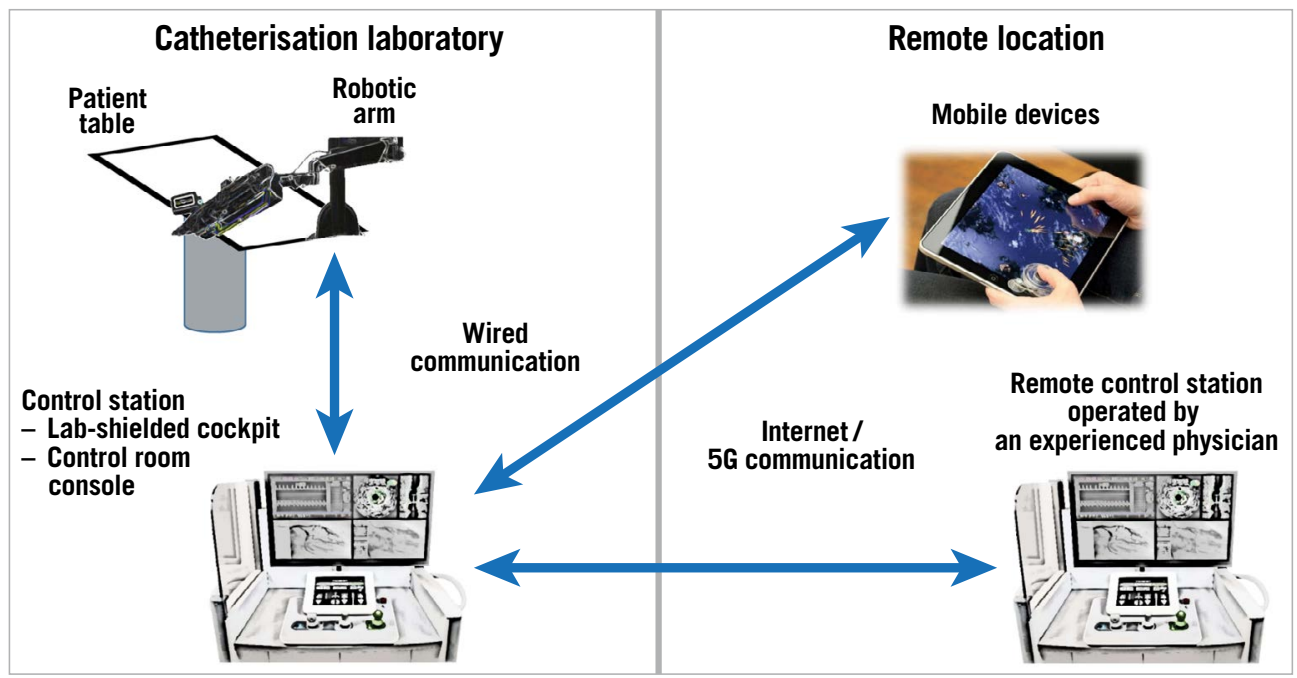

Figure 4. Local and remote schematics. The robotic arm, located in the catheterisation laboratory, is hard-wired to the control station, which can be placed either in the catheterisation laboratory or in the control room, according to the operator's preference. A second remote control unit, which can also be installed on a mobile device, is connected through the internet or a $5 G$ wireless connection and can be placed in any other location (i.e., either elsewhere in the same or a different hospital, or any location worldwide).

\section{ROBOTIC NEUROINTERVENTIONS}

Robotics for vascular neurointerventions based on the cardiovascular experience have been discussed previously ${ }^{81}$. The CorPath GRX system has already been successfully applied to the neurovascular area by advancing the microcatheter, micro stent, and multiple coils to close a large aneurysm in the basilar artery ${ }^{82}$. The researchers concluded that neuro-endovascular intervention using robotic assistance is feasible, offers improved precision, and opens up future possibilities for remote interventions, such as emergency thrombectomy for stroke.

While the CorPath GRX can accommodate most available devices, a dedicated neurovascular system is needed that can handle the major devices used in this field and provide remote internet capabilities. Madder et $\mathrm{al}^{80}$ have pointed out that such a system could be used to solve the problem of geographical disparities and the lack of expert neurovascular interventionalists, as previously discussed ${ }^{83}$. Rabinovich et $\mathrm{al}^{84}$ discussed current and future directions using robotics for neurointerventions. AI-enhanced robotic neurointerventions have the capability to uncover new dimensions within the realm of cerebrovascular therapeutics.

\section{AUTOMATION}

Automated wire manipulation can be a major tool to enhance procedure efficiency by the operators. A special "retract and rotate" feature has already been included in the current CorPath GRX system, and is good for navigating through side branches ${ }^{85}$. Other wire navigation features such as spin and wiggle, as well as device "dottering" applications have already been implemented and used in patients ${ }^{86}$. Visualisation and navigation using virtual reality could be combined with robotics ${ }^{87}$, and full automation of wire navigation via image-based analysis and machine learning would enhance our performance and provide important platforms for parts of the procedure ${ }^{30}$. The next clinical trials should be planned, not only to prove the non-inferiority of robotic PCI, but also to determine definitively the superiority of robotic versus manual PCI, as well as to define possible measurable clinical endpoints to demonstrate overall benefit for both patients and medical staff.

We anticipate a number of benefits from using AI for robotic PCI: software training of new and intermediate users for optimal device manipulation based on the tracked movements of highly skilled operators, advanced integration with the tracking of other robotic coronary devices, development of on-line computational methods for precise selection of projection angles, and solutions for decreasing X-ray dose as well as procedure time.

\section{HAPTICS}

Compensating for the lack of haptics in today's endovascular interventions is the precise and detailed visual feedback during fluoroscopy of the wire tip, stent, and guiding catheter movements. Nevertheless, there may be a need for haptic feedback in certain procedures such as total occlusions, where the pressure of a stiff wire is clearly felt by the operator. The safety of wire manipulation using the robotic arm with software programmed movements needs to be fully examined, both with and without haptics, to determine adverse outcomes such as dissections or perforation.

\section{THE FUTURE OF VASCULAR ROBOTICS}

Overviewing the milestones achieved in robotic PCI since the original concept of remote control navigation for coronary interventions $\mathrm{s}^{54,55}$ shows that the original coronary applications, which were improved following the FDA-approved versions ${ }^{57,60}$, have further expanded to peripheral, carotid, and intracranial procedures. The remote milestone achieved in India ${ }^{79}$ needs to be further assessed in well-designed controlled studies in order to show its added value to expand the access to urgent stroke care. It is clear that robotic coronary, endovascular, and neuro-endovascular interventions are going to have increasing roles in the catheterisation laboratories of the future ${ }^{88}$. 
There are already additional endovascular robotic technologies that are in various phases of development. The R-One ${ }^{\mathrm{TM}}$ system (Robocath, Rouen, France) is in clinical trials in Europe, and the Liberty ${ }^{\mathrm{TM}}$ disposable vascular robot (Microbot, Yokneam, Israel) is in the preclinical phase of development. Patient benefit, radiation protection, and ergonomics will be the leading factors for future robotics.

The ability to perform remote procedures has been proven for both wired and wireless communication. Enhanced by partial automation using machine learning and AI, remote operations may become an integral part of our interventional procedures. We anticipate a number of benefits to the operators and eventually to our patients. One such benefit is the possibility to standardise performance of PCI by using advanced robotic controls to guide and move coronary wires in complex cases and for side branch access, with less dependence on operator experience. In addition, $\mathrm{AI}$ and machine learning provide opportunities for better outcomes by enabling good preprocedural PCI planning. In addition, it may allow remote guidance for the local operator by an experienced distant operator, or even performing of PCI by a skilled operator via full remote guidance. Furthermore, remote procedures may allow the provision of advanced emergency coronary or neurological interventions by enabling access to top operators in different time zones, as well as offering advanced coronary, peripheral, and neurological interventions by skilled operators in underserved areas with a limited number of highly specialised doctors.

The potential for robotic percutaneous valvular interventions has not yet been applied to patients. Surgical robotic techniques for mitral valve repair and coronary bypass surgery have been studied previously but are not widely used except in highly dedicated centres. Robotics will also play an important role in the future education and training of students, fellows of coronary, peripheral, and neurointerventional procedures, as well as the nurses and technicians who are involved in robotic interventions in catheterisation laboratories.

\section{SUMMARY AND CONCLUSION}

The basics of transcatheter interventions rest in our ability to visualise, diagnose, and interpret the X-ray images obtained throughout the procedure. This review, focusing on coronary interventions, has presented a continuum of progress in the cardiac catheterisation laboratory, aimed at improving patient care in interventional cardiology. Image acquisition and presentation in the catheterisation laboratory is constantly improving, and there has been major progress in reducing the amount of radiation exposure to both staff and patients. Co-registration of multimodality imaging may have an increasing role in the future. $\mathrm{AI}$ and machine learning are being used today in the research and clinical settings, and both have great potential for becoming tools central to our decision-making process. Robotics has finally entered the realm of coronary interventions and is becoming an important tool in the catheterisation laboratory, protecting operators from radiation and facilitating precise complex procedures without compromising safety. The potential for AI-enhanced operations and remote robotics across the internet might add to our future practice in remote areas, for cardiovascular and coronary interventions, as well as in neural interventions for stroke, aneurysm, and more.

An overview of such an integrated approach was presented by Sardar et $\mathrm{al}^{30}$ and is shown in Figure 5. Our ultimate goal is to achieve the integration of multiple imaging modalities, AI, online

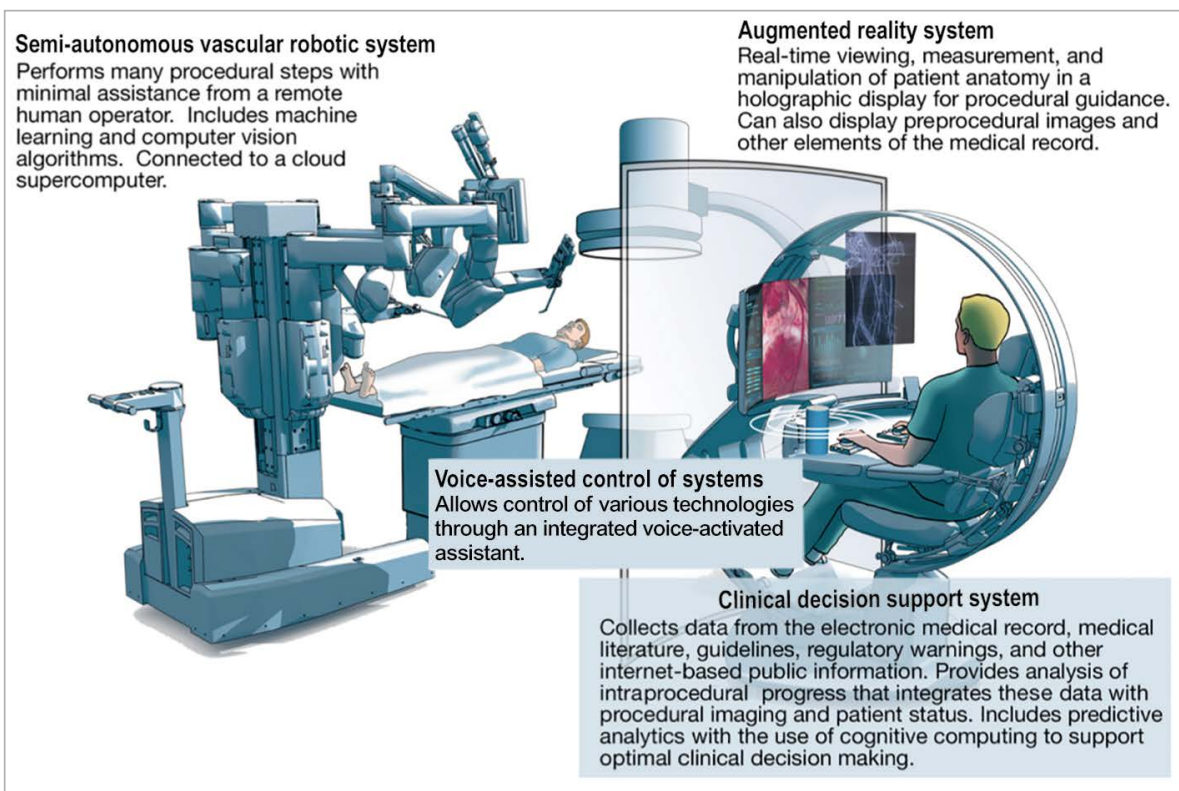

Figure 5. The future catheterisation laboratory with artificial intelligence-enabled technology, clinical decision support system, voice-powered virtual assistant, and augmented reality platforms. A semi-autonomous/autonomous robotic system can provide optimisation as well as the remote operations presented above. Reprinted from Figure 2 of Sardar et al ${ }^{30}$, copyright (2019), with permission from Elsevier. 
clinical decision support systems, voice-powered virtual assistants, augmented reality platforms, and semi-autonomous/autonomous robotic systems that will become the backbone of individualised patient care.

In conclusion, advances in imaging in the catheterisation laboratory are revolutionising the way we process and interpret angiographic X-ray images, integrate them with other imaging modalities, and use AI for better diagnosis and management. In parallel, novel methods for image processing and intelligent systems are being used to reduce X-ray exposure. Robotics has begun to enter the field of interventional cardiology and is now expanding towards peripheral vessels and neurovascular interventions, allowing dramatic radiation reduction, optimal and convenient visibility with subsequent enhanced precision, and preparing the catheterisation laboratory for automation using AI and machine learning.

\section{Conflict of interest statement}

R. Beyar is the co-founder of Corindus, though he has no relationship with the company today; he also holds equity in and is the director/stockholder at MedHub, CardiacSense, Codiguide, Magenta, Cardiac Success, and Bio-T. C. Cook is a consultant for Philips and Boston Scientific, and has equity in Cerebria. D. Dudek has received grants and personal fees from the following entities: Boston, Philips, Abbott, Medtronic, and Biotronik. He has received grants only from Terumo and Bracco. The other authors have no conflicts of interest to declare.

\section{References}

1. Rensing BJ, Hermans WR, Beatt KJ, Laarman GJ, Suryapranata H, van den Brand M, de Feyter PJ, Serruys PW. Quantitative angiographic assessment of elastic recoil after percutaneous transluminal coronary angioplasty. Am J Cardiol. 1990;66: 1039-44.

2. Serruys PW, de Jaegere P, Kiemeneij F, Macaya C, Rutsch W, Heyndrickx G, Emanuelsson H, Marco J, Legrand V, Materne P, et al. A comparison of balloonexpandable-stent implantation with balloon angioplasty in patients with coronary artery disease. Benestent Study Group. N Engl J Med. 1994;331:489-95.

3. Figini F, Louvard Y, Sheiban I. Stent Enhancement during Percutaneous Coronary Intervention: Current Role, Technical Tips and Case Examples. Cardiovasc Revasc Med. 2020;21:137-43

4. Piayda K, Kleinebrecht L, Afzal S, Bullens R, Ter Horst I, Polzin A, Veulemans V, Dannenberg L, Wimmer AC, Jung C, Bönner F, Kelm M, Hellhammer K, Zeus T. Dynamic coronary roadmapping during percutaneous coronary intervention: a feasibility study. Eur J Med Res. 2018;23:36.

5. Yabe T, Muramatsu T, Tsukahara R, Nakano M, Takimura H, Kawano M, Hada T, Ikeda $\mathrm{T}$. The impact of percutaneous coronary intervention using the novel dynamic coronary roadmap system. Heart Vessels. 2020;35:323-30.

6. Ribeiro JM, Hokken T, Astudillo P, Nuis RJ, de Backer O, Rocatello G, Daemen J, van Mieghem NM, Cummins P, de Beule M, Lumens J, Bruining N, de Jaegere PJ. Artificial intelligence and advanced computer modelling in transcatheter interventions for structural heart disease - implications for clinical practice. ESC Digital Health (Virtual Journal). 2020 January 13. Available at: https://www.escardio.org/Education/ Digital-Health-and-Cardiology/Virtual-Journal/artificial-intelligence-and-advancedcomputer-modelling-in-transcatheter-interve. Accessed: 19 January 2021.

7. Liu L, Yang W, Nagahara Y, Li Y, Lamooki SR, Muramatsu T, Kitslaar P, Sarai M, Ozaki Y, Barlis P, Yan F, Reiber JH, Tu S. The impact of image resolution on computation of fractional flow reserve: coronary computed tomography angiography versus 3-dimensional quantitative coronary angiography. Int J Cardiovasc Imaging. 2016;32:513-23.

8. Tomaniak M, Katagiri Y, Modolo R, de Silva R, Khamis RY, Bourantas CV, Torii R, Wentzel JJ, Gijsen FJH, van Soest G, Stone PH, West NEJ, Maehara A, Lerman A, van der Steen AFW, Lüscher TF, Virmani R, Koenig W, Stone GW, Muller JE, Wijns W, Serruys PW, Onuma Y. Vulnerable plaques and patients: state-of-the-art. Eur Heart J. 2020;41:2997-3004.
9. Pu J, Mintz GS, Brilakis ES, Banerjee S, Abdel-Karim AR, Maini B, Biro S, Lee JB, Stone GW, Weisz G, Maehara A. In vivo characterization of coronary plaques: novel findings from comparing greyscale and virtual histology intravascular ultrasound and near-infrared spectroscopy. Eur Heart J. 2012;33:372-83.

10. Puri R, Madder RD, Madden SP, Sum ST, Wolski K, Muller JE, Andrews J, King KL, Kataoka Y, Uno K, Kapadia SR, Tuzcu EM, Nissen SE, Virmani R, Maehara A, Mintz GS, Nicholls SJ. Near-Infrared Spectroscopy Enhances Intravascular Ultrasound Assessment of Vulnerable Coronary Plaque: A Combined Pathological and In Vivo Study. Arterioscler Thromb Vasc Biol. 2015;35:2423-31.

11. Raggi P, Pontone G, Andreini D. Role of new imaging modalities in pursuit of the vulnerable plaque and the vulnerable patient. Int J Cardiol. 2018;250:278-83.

12. Cademartiri F, Maffei E. Cardiac CT for the detection of vulnerable plaque. Eur Heart J Cardiovasc Imaging. 2016;17:260-1

13. Nicol ED, Norgaard BL, Blanke P, Ahmadi A, Weir-McCall J, Horvat PM, Han K, Bax JJ, Leipsic J. The Future of Cardiovascular Computed Tomography: Advanced Analytics and Clinical Insights. JACC Cardiovasc Imaging. 2019;12:1058-72.

14. Corral-Acero J, Margara F, Marciniak M, Rodero C, Loncaric F, Feng Y, Gilbert A, Fernandes JF, Bukhari HA, Wajdan A, Martinez MV, Santos MS, Shamohammdi M, Luo H, Westphal P, Leeson P, DiAchille P, Gurev V, Mayr M, Geris L, Pathmanathan P, Morrison T, Cornelussen R, Prinzen F, Delhaas T, Doltra A, Sitges M, Vigmond EJ, Zacur E, Grau V, Rodriguez B, Remme EW, Niederer S, Mortier P, McLeod K, Potse M, Pueyo E, Bueno-Orovio A, Lamata P. The 'Digital Twin' to enable the vision of precision cardiology. Eur Heart J. 2020;41:4556-64.

15. Attia ZI, Noseworthy PA, Lopez-Jimenez F, Asirvatham SJ, Deshmukh AJ, Gersh BJ, Carter RE, Yao X, Rabinstein AA, Erickson BJ, Kapa S, Friedman PA. An artificial intelligence-enabled ECG algorithm for the identification of patients with atrial fibrillation during sinus rhythm: a retrospective analysis of outcome prediction. Lancet. 2019;394:861-7.

16. Zhang J, Gajjala S, Agrawal P, Tison GH, Hallock LA, Beussink-Nelson L, Lassen MH, Fan E, Aras MA, Jordan C, Fleischmann KE, Melisko M, Qasim A, Shah SJ, Bajcsy R, Deo RC. Fully Automated Echocardiogram Interpretation in Clinical Practice. Circulation. 2018;138:1623-35.

17. Bond R, Peace A. Near future artificial intelligence in interventional cardiology: new opportunities and challenges to improve the care of STEMI patients. ESC Digital Health (Virtual Journal). 2020 March 31. Available at: https://www.escardio.org/ Education/Digital-Health-and-Cardiology/Virtual-Journal/near-future-artificial-intelligence-in-interventional-cardiology-new-opportunit. Accessed: 19 January 2021.

18. Johnson KW, Torres Soto J, Glicksberg BS, Shameer K, Miotto R, Ali M, Ashley E, Dudley JT. Artificial Intelligence in Cardiology. J Am Coll Cardiol. 2018;71:2668-79. 19. Noseworthy PA, Attia ZI, Carter RE, Yao X, Friedman PA. An AI-ECG algorithm for atrial fibrillation risk: steps towards clinical implementation - Authors' reply. Lancet. 2020;396:236-7.

20. van der Hoeven BL, Schalij MJ, Delgado V. Multimodality imaging in interventional cardiology. Nat Rev Cardiol. 2012;9:333-46.

21. Ghoshhajra BB, Takx RAP, Stone LL, Girard EE, Brilakis ES, Lombardi WL, Yeh RW, Jaffer FA. Real-time fusion of coronary CT angiography with x-ray fluoroscopy during chronic total occlusion PCI. Eur Radiol. 2017;27:2464-73.

22. Michail M, Serruys PW, Stettler R, Crake T, Torii R, Tenekecioglu E, Zeng Y, Onuma Y, Mathur A, Bourantas CV. Intravascular multimodality imaging: feasibility and role in the evaluation of coronary plaque pathology. Eur Heart J Cardiovasc Imaging. 2017;18:613-20.

23. Goreczny S, Dryzek P, Morgan GJ, Lukaszewski M, Moll JA, Moszura T. Novel Three-Dimensional Image Fusion Software to Facilitate Guidance of Complex Cardiac Catheterization. Pediatr Cardiol. 2017;38:1133-42.

24. Arar Y, Reddy SRV, Kim H, Dimas VV, Zellers TM, Abou Zahr R, Vamsee R, Greer JS, Tandon A, Pontiki A, Dillenbeck J, Zabala L, Greil G, Nugent AW, Hussain T. $3 \mathrm{D}$ advanced imaging overlay with rapid registration in CHD to reduce radiation and assist cardiac catheterisation interventions. Cardiol Young. 2020;30:656-62.

25. Kasprzak JD, Witowski J, Pawlowski J, Peruga JZ, Zlahoda-Huzior A. Percutaneous patent ductus arteriosus closure using intraprocedural mixed reality visualization of $3 \mathrm{D}$ computed tomography angiography data: first-in-man experience. Eur Heart $J$ Cardiovasc Imaging. 2019;20:839.

26. Kasprzak JD, Pawlowski J, Peruga JZ, Kaminski J, Lipiec P. First-in-man experience with real-time holographic mixed reality display of three-dimensional echocardiography during structural intervention: balloon mitral commissurotomy. Eur Heart J. 2020;41:801

27. Banchhor SK, Londhe ND, Araki T, Saba L, Radeva P, Khanna NN, Suri JS Calcium detection, its quantification, and grayscale morphology-based risk stratification using machine learning in multimodality big data coronary and carotid scans: A review. Comput Biol Med. 2018;101:184-98

28. Krittanawong C, Zhang H, Wang Z, Aydar M, Kitai T. Artificial Intelligence in Precision Cardiovascular Medicine. J Am Coll Cardiol. 2017;69:2657-64. 
29. Tomasik A, Mlynczak T, Nowak E, Pigon K, Iwasieczko A, Opara M, NowalanyKozielska E. Quantitative myocardial blush score (QuBE) allows the prediction of heart failure development in long-term follow-up in patients with ST-segment elevation myocardial infarction: Proof of concept study. Cardiol J. 2019;26:322-32.

30. Sardar P, Abbott JD, Kundu A, Aronow HD, Granada JF, Giri J. Impact of Artificial Intelligence on Interventional Cardiology: From Decision-Making Aid to Advanced Interventional Procedure Assistance. JACC Cardiovasc Interv. 2019;12:1293-303.

31. Cates CU, Gallagher AG. The future of simulation technologies for complex cardiovascular procedures. Eur Heart J. 2012;33:2127-34.

32. Litjens G, Ciompi F, Wolterink JM, de Vos BD, Leiner T, Teuwen J, Išgum I. Stateof-the-Art Deep Learning in Cardiovascular Image Analysis. JACC Cardiovasc Imaging. 2019;12:1549-65.

33. Roguin A, Abu Dogosh A, Feld Y, Konigstein M, Lerman A, Koifman E. Early Feasibility of Automated Artificial Intelligence Angiography Based Fractional Flow Reserve Estimation. Am J Cardiol. 2021;139:8-14.

34. U.S. Food \& Drug Administration, Center for Devices and Radiological Health. Artificial intelligence and machine learning in software as a medical device. 2021; January. Available at: https://www.fda.gov/MedicalDevices/DigitalHealth/Softwareasa MedicalDevice/ucm634612.htm. Accessed 19 January 2021.

35. Parisot C. The DICOM standard. A breakthrough for digital information exchange in cardiology. Int J Card Imaging. 1995;11:171-7.

36. Ioannidis JP. Stealth research: is biomedical innovation happening outside the peerreviewed literature? JAMA. 2015;313:663-4.

37. Allen B. The Role of the FDA in Ensuring the Safety and Efficacy of Artificial Intelligence Software and Devices. J Am Coll Radiol. 2019;16:208-10.

38. Liu X, Rivera SC, Moher D, Calvert MJ, Denniston AK; Spirit AI, CONSORT-AI Working Group. Reporting guidelines for clinical trial reports for interventions involving artificial intelligence: the CONSORT-AI Extension. BMJ. 2020;370:m3164.

39. Brilakis ES. Innovations in Radiation Safety During Cardiovascular Catheterization. Circulation. 2018;137:1317-9.

40. Balter S, Simon D, Itkin M, Granada JF, Melman H, Dangas G. Significant radiation reduction in interventional fluoroscopy using a novel eye controlled movable region of interest. Med Phys. 2016;43:1531-8.

41. Ciusdel C, Turcea A, Puiu A, Itu L, Calmac L, Weiss E, Margineanu C, Badila E, Berger M, Redel T, Passerini T, Gulsun M, Sharma P. Deep neural networks for ECG free cardiac phase and end-diastolic frame detection on coronary angiographies. Comput Med Imaging Graph. 2020;84:101749.

42. Howard JP, Cook CM, van de Hoef TP, Meuwissen M, de Waard GA, van Lavieren MA, Echavarria-Pinto M, Danad I, Piek JJ, Götberg M, Al-Lamee RK, Sen S, Nijjer SS, Seligman H, van Royen N, Knaapen P, Escaned J, Francis DP, Petraco R, Davies JE. Artificial Intelligence for Aortic Pressure Waveform Analysis During Coronary Angiography: Machine Learning for Patient Safety. JACC Cardiovasc Interv. 2019;12:2093-101.

43. Cook CM, Warisawa T, Howard JP, Keeble TR, Iglesias JF, Schampaert E, Bhindi R, Ambrosia A, Matsuo H, Nishina H, Kikuta Y, Shiono Y, Nakayama M, Doi S, Takai M, Goto S, Yakuta Y, Karube K, Akashi YJ, Clesham GJ, Kelly PA, Davies JR, Karamasis GV, Kawase Y, Robinson NM, Sharp ASP, Escaned J, Davies JE. Algorithmic Versus Expert Human Interpretation of Instantaneous Wave-Free Ratio Coronary Pressure-Wire Pull Back Data. JACC Cardiovasc Interv. 2019;12:1315-24.

44. George EI, Brand TC, LaPorta A, Marescaux J, Satava RM. Origins of Robotic Surgery: From Skepticism to Standard of Care. JSLS. 2018;22:e2018.00039.

45. Himpens J, Leman G, Cadiere GB. Telesurgical laparoscopic cholecystectomy. Surg Endosc. 1998;12:1091.

46. Marescaux J, Leroy J, Gagner M, Rubino F, Dutter D, Vix M, Butner SE, Smith MK. Transatlantic robot-assisted telesurgery. Nature. 2001;413:379-80.

47. Grüntzig AR, Senning A , Siegenthaler WE. Nonoperative dilatation of coronaryartery stenosis: percutaneous transluminal coronary angioplasty. $N$ Engl $\mathrm{J} \mathrm{Med}$. 1979;301:61-8.

48. Balter S. Radiation safety in the cardiac catheterization laboratory: operational radiation safety. Catheter Cardiovasc Interv. 1999;47:347-53.

49. Roguin A, Goldstein J, Bar O. Brain tumours among interventional cardiologists: a cause for alarm? Report of four new cases from two cities and a review of the literature. EuroIntervention. 2012;7:1081-6.

50. Vano E, Kleiman NJ, Duran A, Rehani MM, Echeverri D, Cabrera M. Radiation cataract risk in interventional cardiology personnel. Radiat Res. 2010;174:490-5.

51. Ross AM, Segal J, Borenstein D, Jenkins E, Cho S. Prevalence of spinal disc disease among interventional cardiologists. Am J Cardiol. 1997;79:68-70.

52. Tsuchida K, García-García HM, van der Giessen WJ, McFadden EP, van der Eng M, Sianos G, Meulenbrug H, Ong AT, Serruys PW. Guidewire navigation in coronary artery stenosis using a novel magnetic navigation system: first clinical experience. Catheter Cardiovasc Interv. 2006;67:356-63.
53. Kiemeneij F, Patterson MS, Amoroso G, Laarman GJ, Slagboom T. Use of the Stereotaxis Niobe magnetic navigation system for percutaneous coronary intervention: results from 350 consecutive patients. Catheter Cardiovasc Interv. 2008;71:510-6.

54. Beyar R, Wenderow T, Lindner D, Kumar G, Shofti R. Concept, design and preclinical studies for remote control percutaneous coronary interventions. EuroIntervention. 2005;1:340-5.

55. Beyar R, Gruberg L, Deleanu D, Roguin A, Almagor Y, Cohen A, Kumar G, Wendrow T. Remote-control percutaneous coronary interventions: concept, validation, and first-in-humans pilot clinical trial. J Am Coll Cardiol. 2006;47:296-300.

56. Granada JF, Delgado JA, Uribe MP, Fernandez A, Blanco G, Leon MB, Weisz G. First-in-human evaluation of a novel robotic-assisted coronary angioplasty system. JACC Cardiovasc Interv. 2011;4:460-5.

57. Weisz G, Metzger DC, Caputo RP, Delgado JA, Marshall JJ, Vetrovec GW, Reisman M, Waksman R, Granada JF, Novack V, Moses JW, Carrozza JP. Safety and feasibility of robotic percutaneous coronary intervention: PRECISE (Percutaneous Robotically-Enhanced Coronary Intervention) Study. J Am Coll Cardiol. 2013;61: 1596-600.

58. Mahmud E, Naghi J, Ang L, Harrison J, Behnamfar O, Pourdjabbar A, Reeves R, Patel M. Demonstration of the Safety and Feasibility of Robotically Assisted Percutaneous Coronary Intervention in Complex Coronary Lesions: Results of the CORA-PCI Study (Complex Robotically Assisted Percutaneous Coronary Intervention). JACC Cardiovasc Interv. 2017;10:1320-7

59. Harrison J, Ang L, Naghi J, Behnamfar O, Pourdjabbar, Patel MP, Reeves RR, Mahmud E. Robotically-assisted percutaneous coronary intervention: Reasons for partial manual assistance or manual conversion. Cardiovasc Revasc Med. 2018;19:526-31.

60. Corindus. How it works: CorPath GRX precision vascular robotics. 2021. Website of Corindus. A Siemens Healthineers Company. Available at: https://www.corindus. com/corpath-grx/how-it-works. Accessed 31 January 2021.

61. Smitson CC, Ang L, Pourdjabbar A, Reeves R, Patel M, Mahmud E. Safety and Feasibility of a Novel, Second-Generation Robotic-Assisted System for Percutaneous Coronary Intervention: First-in-Human Report. J Invasive Cardiol. 2018;30:152-6.

62. Mahmud E, Dominguez A, Bahadorani J. First-in-human robotic percutaneous coronary intervention for unprotected left main stenosis. Catheter Cardiovasc Interv. 2016;88:565-70

63. Nagaraja V, Khatri JJ. Hybrid Robotic Impella-Assisted Single Arterial Access Complex High-Risk Percutaneous Coronary Intervention. Cardiovasc Revasc Med. 2020;21:105-7.

64. Almasoud A, Walters D, Mahmud E. Robotically performed excimer laser coronary atherectomy: Proof of feasibility. Catheter Cardiovasc Interv. 2018;92:713-6.

65. Smilowitz NR, Moses JW, Sosa FA, Lerman B, Qureshi Y, Dalton KE, Privitera LT, Canone-Weber D, Singh V, Leon MB, Weisz G. Robotic-Enhanced PCI Compared to the Traditional Manual Approach. J Invasive Cardiol. 2014;26:318-21.

66. Walters D, Reeves RR, Patel M, Naghi J, Ang L, Mahmud E. Complex robotic compared to manual coronary interventions: 6- and 12-month outcomes. Catheter Cardiovasc Interv. 2019;93:613-7.

67. Bezerra HG, Mehanna E, Vetrovec GW, Costa MA, Weisz G. Longitudinal Geographic Miss (LGM) in Robotic Assisted Versus Manual Percutaneous Coronary Interventions. J Interv Cardiol. 2015;28:449-55.

68. Hirai T, Kearney K, Kataruka A, Gosch KL, Brandt H, Nicholson WJ, Lombardi WL, Grantham JA, Salisbury AC. Initial report of safety and procedure duration of robotic-assisted chronic total occlusion coronary intervention. Catheter Cardiovasc Interv. 2020;95:165-9.

69. Walters D, Patel M, Reeves R, Ang L, Al Khiami B, Mahmud E. Planned Robotic Chronic Total Occlusion Percutaneous Coronary Intervention: Feasibility Report. J Invasive Cardiol. 2020;32:201-5.

70. Tabaza L, Virk HUH, Janzer S, George JC. Robotic-assisted percutaneous coronary intervention in a COVID-19 patient. Catheter Cardiovasc Interv. 2021;97:E343-5.

71. Mahmud E, Schmid F, Kalmar P, Deutschmann H, Hafner F, Rief P, Brodmann M Feasibility and Safety of Robotic Peripheral Vascular Interventions: Results of the RAPID Trial. JACC Cardiovasc Interv. 2016;9:2058-64.

72. Wegermann ZK, Swaminathan RV, Rao SV. Cath Lab Robotics: Paradigm Change in Interventional Cardiology? Curr Cardiol Rep. 2019;21:119.

73. Mangels DR, Giri J, Hirshfeld J, Wilensky RL. Robotic-assisted percutaneous coronary intervention. Catheter Cardiovasc Interv. 2017;90:948-55.

74. Mangels D, Fregoso A, Ang L, Mahmud E. Resource Utilization During Elective Robotic-Assisted Percutaneous Coronary Intervention. J Invasive Cardiol. 2020; 32:E321-5.

75. Patel TM, Shah SC, Soni YY, Radadiya RC, Patel GA, Tiwari PO, Pancholy SB Comparison of Robotic Percutaneous Coronary Intervention With Traditional Percutaneous Coronary Intervention: A Propensity Score-Matched Analysis of a Large Cohort. Circ Cardiovasc Interv. 2020;13:e008888. 
76. Eleid MF, Zheng PP, Gulati R, Bergman P, Kottenstette N, Li Y, Lerman A, Sandhu GS. Remote robotic percutaneous coronary intervention: An animal feasibility study. Catheter Cardiovasc Interv. 2021;97:E274-9.

77. Madder RD, VanOosterhout SM, Jacoby ME, Collins S, Borgman AS, Mulder AN, Elmore MA, Campbell JL, McNamara RF, Wohns DH. Percutaneous coronary intervention using a combination of robotics and telecommunications by an operator in a separate physical location from the patient: an early exploration into the feasibility of telestenting (the REMOTE-PCI study). EuroIntervention. 2017;12:1569-76.

78. Madder RD, VanOosterhout S, Mulder A, Bush J, Martin S, Rash A, Tan JM 2nd, Parker J, Li Y, Kottenstette N, Bergman P, Nowak B. Feasibility of robotic telestenting over long geographic distances: a pre-clinical ex vivo and in vivo study. EuroIntervention. 2019;15:e510-2.

79. Patel TM, Shah SC, Pancholy SB. Long Distance Tele-Robotic-Assisted Percutaneous Coronary Intervention: A Report of First-In-Human Experience. EClinicalMedicine. 2019;14:53-8

80. Madder RD, VanOosterhout S, Parker J, Sconzert K, Li Y, Kottenstette N, Madsen A, Sungur JM, Bergman P. Robotic telestenting performance in transcontinental and regional pre-clinical models. Catheter Cardiovasc Interv. 2021;97:E327-32.

81. Menaker SA, Shah SS, Snelling BM, Sur S, Starke RM, Peterson EC. Current applications and future perspectives of robotics in cerebrovascular and endovascular neurosurgery. J Neurointerv Surg. 2018;10:78-82
82. Mendes Pereira V, Cancelliere NM, Nicholson P, Radovanovic I, Drake KE, Sungur JM, Krings T, Turk A. First-in-human, robotic-assisted neuroendovascular intervention. J Neurointerv Surg. 2020;12:338-40.

83. Brinjikji W, Rabinstein AA, Cloft HJ. Socioeconomic disparities in the utilization of mechanical thrombectomy for acute ischemic stroke. J Stroke Cerebrovasc Dis. 2014;23:979-84.

84. Rabinovich EP, Capek S, Kumar JS, Park MS. Tele-robotics and artificial-intelligence in stroke care. J Clin Neurosci. 2020;79:129-32.

85. Al Nooryani A, Aboushokka W. Rotate-on-Retract Procedural Automation for Robotic-Assisted Percutaneous Coronary Intervention: First Clinical Experience. Case Rep Cardiol. 2018;2018:6086034.

86. Zelias A, Khokhar AA, Proniewska K, Zlahoda-Huzior A, Ruggiero R, Chandra K, Giannini F, Dudek D. Percutaneous coronary intervention of a tortuous and complex circumflex lesion using the robotic CorPath GRX system. Kardiol Pol. 2021 Jul 7. [Epub ahead of print].

87. Dugas CM, Schussler JM. Advanced technology in interventional cardiology: A roadmap for the future of precision coronary interventions. Trends Cardiovasc Med. 2016;26:466-73.

88. Chakravartti J, Rao SV. Robotic Assisted Percutaneous Coronary Intervention: Hype or Hope? J Am Heart Assoc. 2019;8:e012743. 